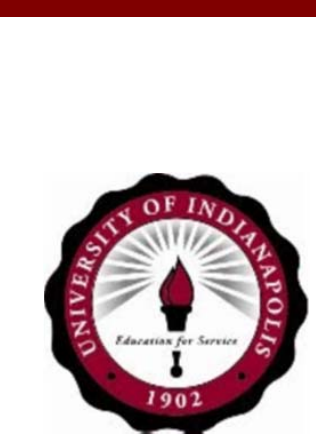

\title{
Self-Compassion, Loneliness, and Well-Being in People Living with HIV
}

Leah M. Bogusch, B.S. ${ }^{1}$, Erin M. Fekete, Ph.D. ${ }^{1}$, Matthew D. Skinta, Ph.D. ${ }^{2}$, Stacey L. Williams, Ph.D. ${ }^{3}$, Nicole M. Taylor, Ph.D. ${ }^{1}$, \& Amanda R. McErlean, M.A. ${ }^{1}$ University of Indianapolis, ${ }^{2}$ Private Practice, San Francisco, CA, ${ }^{3}$ East Tennessee State University First Author Contact Information: boguschl@uindy.edu Principal Investigator Contact Information: feketee@uindy.edu
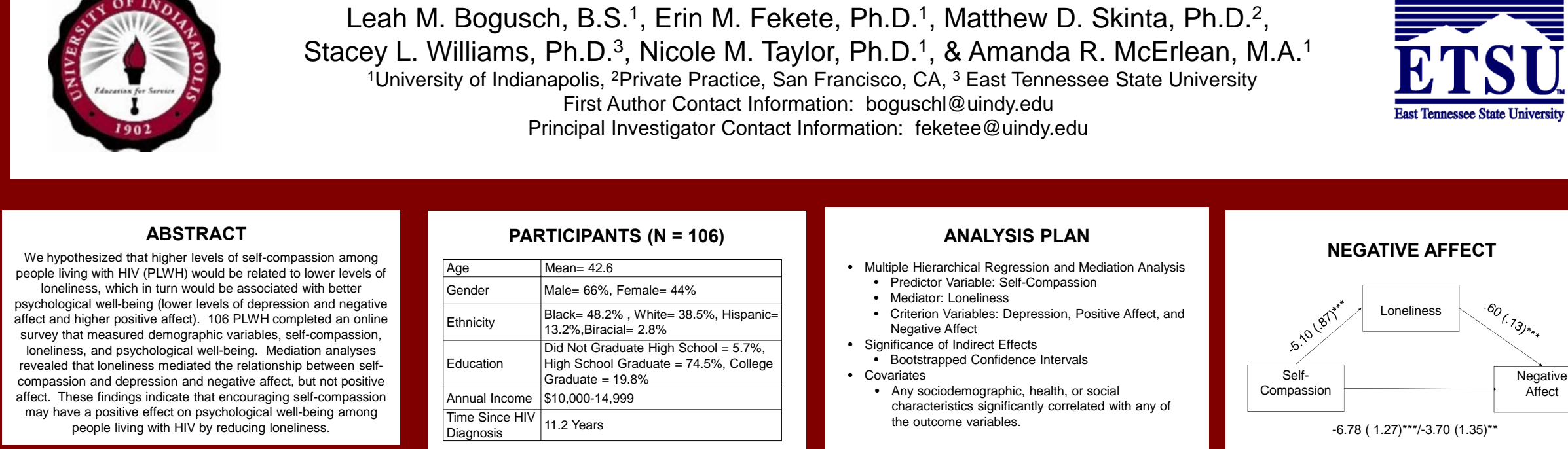

INTRODUCTION

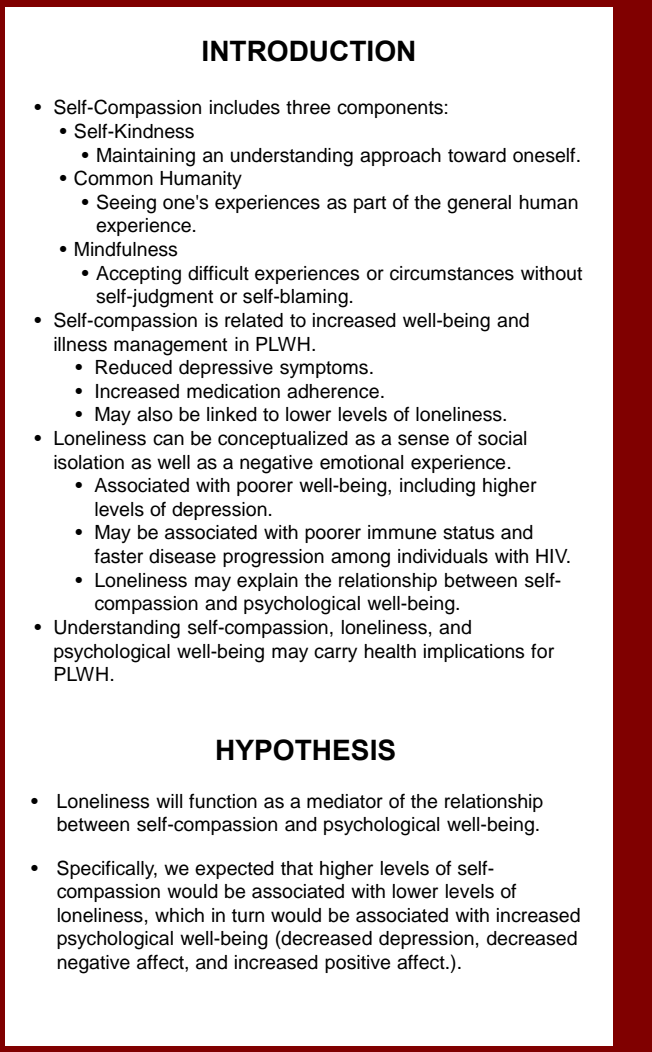

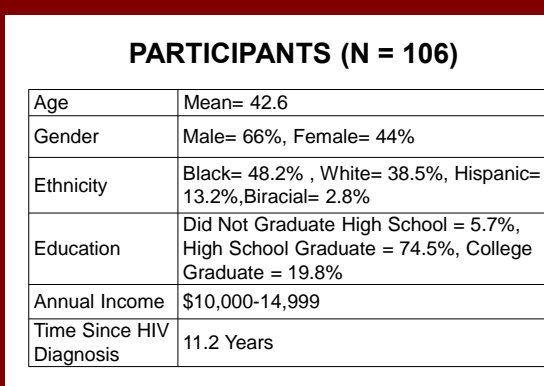

PROCEDURE

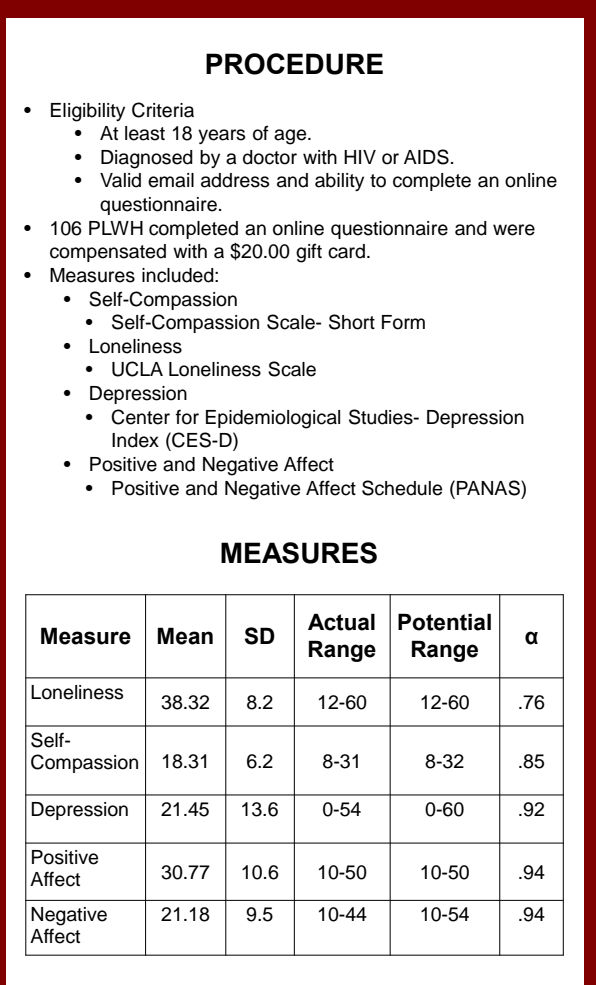

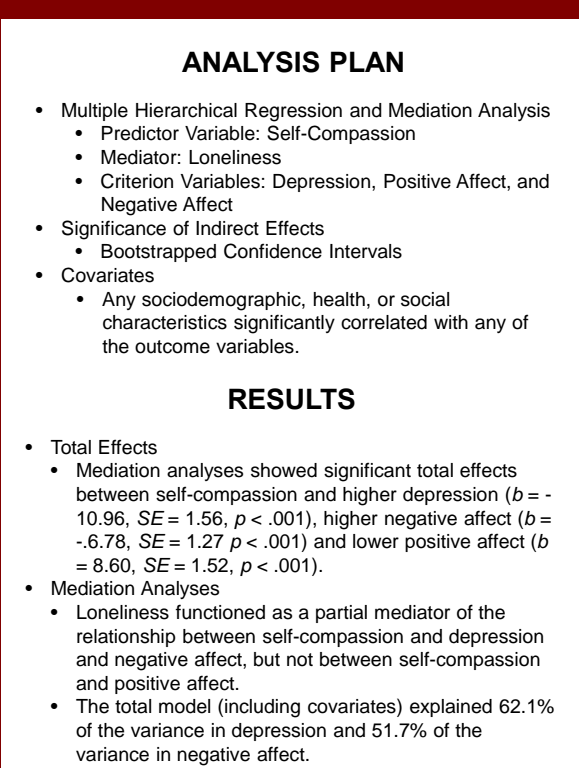

SIGNIFICANCE OF INDIRECT EFFECTS

\begin{tabular}{|l|c|c|}
\hline \multicolumn{1}{|c|}{ Outcome Variable } & $\begin{array}{c}\text { Indirect } \\
\text { Effect }\end{array}$ & $\begin{array}{c}\text { Bootstrapped } \\
\text { Confidence } \\
\text { Interval }\end{array}$ \\
\hline Depression & -3.05 & -5.36 to $-1.29^{\star}$ \\
\hline Negative Affect & -3.13 & -5.10 to $-1.47^{\star}$ \\
\hline Positive Affect & -1.48 & -1.48 to 2.59 \\
\hline
\end{tabular}

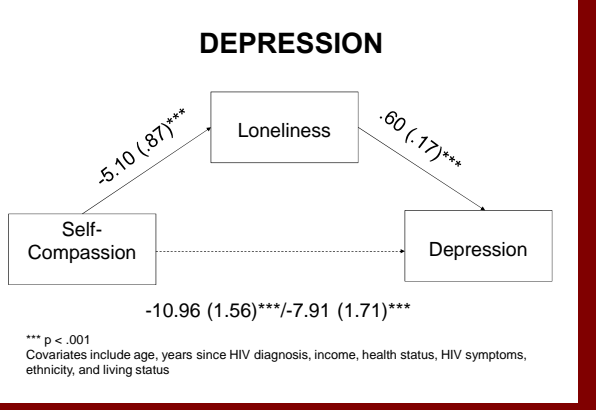

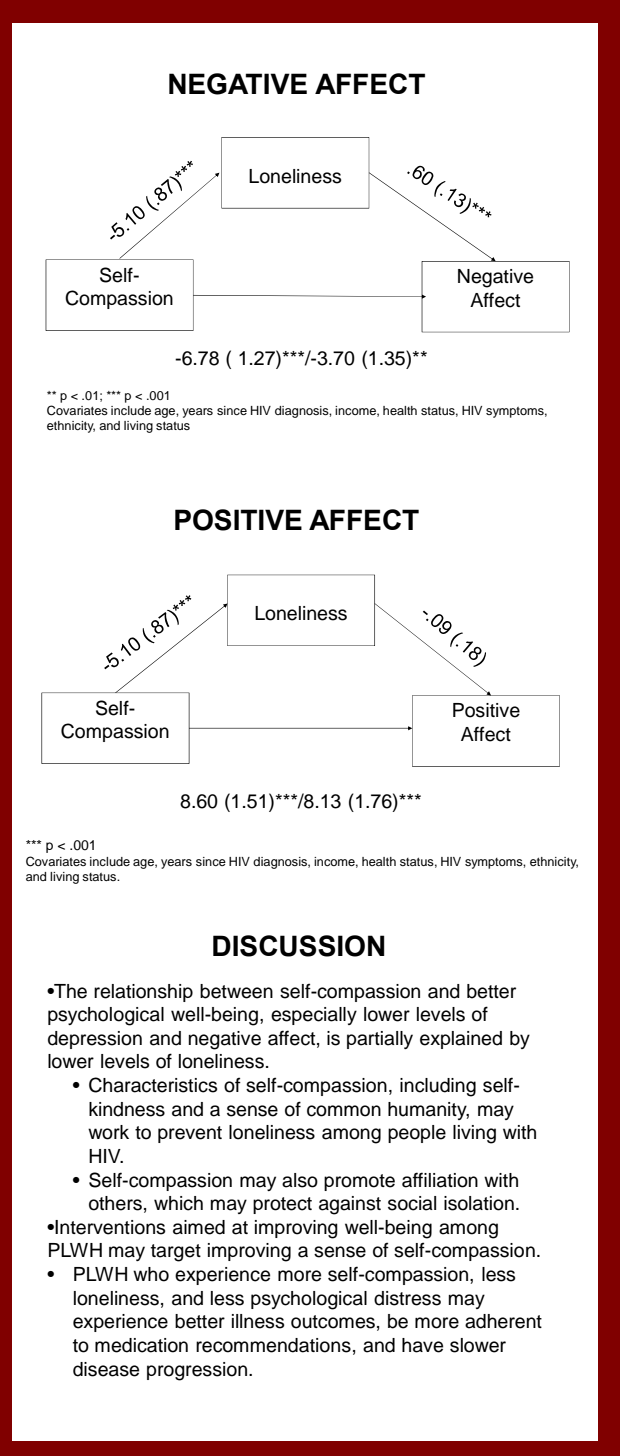

